\title{
A Prediction Method for TBM Cutterhead Dynamic Tunneling Performance under Typical Composite Geological Conditions
}

\author{
Jingxiu Ling ${ }^{1,2, *}$, Xiaojing Yang ${ }^{1,3}$, Zhihong $\mathrm{Wu}^{2}$ \\ ${ }^{1}$ School of Mechanical and Automotive Engineering, Fujian University of Technology, Fuzhou, China \\ ${ }^{2}$ CSCEC Strait Construction and Development Co., Ltd, Fuzhou, China \\ ${ }^{3}$ Mechanical Engineering Practice Training Base, Fujian University of Technology, Fuzhou, China
}

*Corresponding Author: Jingxiu Ling, School of Mechanical and Automotive Engineering, Fujian University of Technology, Fuzhou, China. ljxyxj@ fjut.edu.cn

\begin{abstract}
:
The cutterhead system is a core component of TBM equipment, which works in the extremely severe environment, and the strong impact loads result in severe vibration, crack, damage failure and other engineering failures. Accordingly, the key for cutterhead system structure design and parameter matching is to evaluate and predict cutterhead tunneling per-formance reasonably. In this paper, a prediction method for TBM cutterhead dynamic tunneling performance is pro-posed under the typical composite geological conditions, based on the CSM model of multi-cutters and cutter loads field test data. Then an actual TBM cutterhead of a water conservancy project is taken as an example, a spatial three-dimensional separation zone model for cutterhead tunneling is established under the typical geological condition, and the parameters influence rules of cutterhead tunneling performance are analyzed. The results show that, the cutter-head loads and specific energy change rules with different parameters are basically similar. Moreover, under the condi-tion of penetration $\mathrm{p}=10 \mathrm{~mm}$, the cutterhead bending moment coefficient of variation magnitude exceeds $20 \%$, which is the maximum, and the normal cutter spacing optimal value is $95 \mathrm{~mm}$. Also, when the normal cutter spacing is kept constant in $85 \mathrm{~mm}$, the penetration has a greater influence on the torque and specific energy coefficient of variations, which is increased from $2 \mathrm{~mm}$ to $10 \mathrm{~mm}$, and the two indexes decrease by about $73 \%$. It is indicated that proper increase of pene-tration is beneficial to reduce the vibration fluctuation degree of torque and specific energy. The proposed method of TBM cutterhead dynamic tunneling performance and the analysis results can provide theoretical basis and design refer-ence for TBM cutterhead layout and tunneling parameters matching.

Keywords: TBM cutterhead, spatial geological model, tunneling performance, parameter influence

Citation: J.X. Ling, X.J. Yang, Z.H. Wu. A Prediction Method for TBM Cutterhead Dynamic Tunneling Performance under Typical Composite Geological Conditions. Mech Eng Sci, 2019,1(1): 33-41. https://doi.org/10.33142/me.v1i1.659
\end{abstract}

\section{Introduction}

Cutterhead system is a key working component of the full face hard rock Tunnel Boring Machine (TBM), which endures strong, random, and multi-point distributed impact loads, leading to structure vibration, fatigue, crack damage and other mechanical failures (Huo et al., 2017; Cai, et al., 2017). Hence, accurate analysis and evaluation of cutterhead loads are closely related to the whole machine control parameters matching, system dynamic as well as the key structure fatigue life prediction. Besides, it may indirectly affect the construction efficiency and safety. Moreover, the energy consumption prediction of rock breaking by cutter is also a key point of TBM. Due to the random variability of surrounding rock in excavation interface and tunneling direction, the TBM cutterhead force and load transfer condition are extremely complicated. Accordingly it is difficult to accurately evaluate the cutterhead excavation performance. However, it is necessary to predict and analyze the cutterhead dynamic excavation performance in the design stage, according to the geologic exploration report, so as to achieve the purpose of component structure optimization and tunneling parameters matching.

In view of the problems above-mentioned, relevant scholars have done a lot of research. Many researchers have proposed different prediction models to estimate the cutting forces, with the means of theoretical derivation, test and numerical simulation. Previous attempts to measure cutting forces (i.e., normal, rolling, and side force) in the field and laboratory were carried out by Samuel and Seow (1984), Rostami (1997), Zhang et al. (2003) and Gertsch et al. (2007). These studies gave valuable insight into the rock breaking mechanism and load change regulation of an 
individual disk cutter. However, different types of disc cutters were mounted on the cutterhead, and with different installation locations, the change regulation of cutting forces were not the same. Moreover, in all these studies, the normal disc cutters were mostly used, and the gage cutters were rarely studied. Accordingly, a new cutter force measurement method was proposed by Entacher et al. (2013), and it was implemented at Koralm tunnel. Later, a series of punch penetration tests were performed by Jeong et al. (2015), to estimate the disc cutter's normal force, and the results were validated by a LCM test. Considering the circular running path and wear of the disc cutter, a new cutter force model was developed by Yang et al. (2013), which was also compared with the classical models. Besides, with the rapid development of numerical simulation technology, many researchers carried out lots of CAE analyses to simulate the rock breaking process. A 3D FEM-SPH coupling method was applied to study the rock fragmentation mechanism by Nan et al. (2015). Meanwhile, Liu et al. (2015), Geng et al. (2017), Xia et al. (2017) and Jiang et al. (2017) respectively simulated the rock cutting process by the methods of FEM and DEM, to obtain the cutter forces and the optimal cutter spacing, as well as establish foundation for cutterhead performance prediction. Some scholars studied the rock cutting process based on numerical simulation and rotary cutting experiments (Xia et al., 2016; Geng et al., 2016), to provide reference for side force formation mechanism and cutters layout.

For a long time, many earlier models and studies have also been carried out about cutterhead loads, cutterhead system design and specific energy. Zhu et al. (2014) studied the excavating loads characteristic on TBM cutterhead, and the parameters influence on cutterhead loads was analyzed. A new cutterhead load model was established based on the CSM model and rock section circular hierarchical model, then the cutterhead force distribution under certain geology was calculated (Liu et al., 2016 and 2017). The cylinders thrust force and cutterhead loads were respectively presented by Huang et al. (2016) and Han et al. (2017), based on the theoretical derivation and simulation method, which can provide important theoretical basis and a reference for the design and parameters control during TBM construction. The cutterhead system design for the hard rock TBM was studied by Rostami (2008), and it pointed out that the cutters distribution was critical to cutterhead balance performance. A calculation model was built to study the TBM cutterhead mechanical performance in mixed rock ground conditions, and it was verified with a boring experiment (Geng et al., 2016). They also proposed a free-face-assisted rock breaking method based on a multi-stage TBM cutterhead, to improve the TBM rock breaking efficiency (Geng et al., 2016). Huo et al. $(2015,2016)$ studied the multi-directional coupling dynamic characteristics of TBM cutterhead system, to lay a foundation of cutterhead structural design and system parameters matching. Avunduk and Copur (2018) developed empirical performance prediction models for predicting a EPB TBM excavation performance, and field tests were carried out to validate these proposed models. The specific energy (SE) is another important performance parameter, and many scholars have studied it with different methods in different tunnels (Wang et al., 2012; Mirahmadi et al., 2017).

As mentioned above, scholars have studied cutter force prediction, cutterhead loads and system design, specific energy and so on, by using the methods of theoretical derivation, numerical simulation, and model experiment, as well as field test. However, in the previous studies, it was assumed that the formation was single and homogeneous or two element circular cross-section model while predicting the cutter forces. It was inappropriate since the results ignored the cutter forces impact-resistance, time variation of the cutter's surrounding rock in excavation section and the formation random variation. Besides, the rock breaking loads change is closely related to the cutter location and tunneling parameters. The dynamic parameters changes need to be considered while solving the cutterhead loads and specific energy, and then the performance indexes can be obtained. For this, in this study, a spatial three-dimensional separate surrounding rock model under an actual typical tunnel is established, based on the geological exploration data. That is, the rock physical properties in different tunneling sections are all different. Meanwhile, a prediction method for TBM cutterhead excavation performance under typical geological conditions is proposed, considering the TBM tunneling parameters, cutters position information and the dynamic changes of surrounding rock property at different time, based on the CSM model and cutter loads field test data (Samuel and Seow, 1984; Zhang, et al., 2003). In this study, the cutterhead loads and specific energy are used to quantify the excavation performance. Last, taking a water diversion project as an example, the dynamic cutter loads, cutterhead loads and specific energy are obtained with the proposed method. And the influences of normal cutter spacing and penetration on cutterhead excavation performance are analyzed, which can provide reference for TBM cutterhead layout and tunneling parameters matching.

\section{Theoretical calculation model of cutterhead ex- cavation performance}

When the TBM tunnels, the cutterhead endures strong, multipoint distributed impact loads, which leads to intense vibration. After all the cutters loads are combined, the cutterhead mainly bears the thrust $P_{v}$, radial force $P_{r}$, torque $T$ and the bending moment $M$, as shown in Figure 1. Accordingly, the cutterhead loads can be obtained with the information of cutters locations, installation angles and surrounding rock physical properties under the typical condition. In addition, the relational schematic diagram between the cutter force and layout position is shown in Figure 2. In this figure, the cutter normal force, tangential force and side force are denoted as $F_{v}, F_{r}$ and $F_{s}$, respectively, $l$ is the cutter polar radius, $\theta$ is the cutter phase angle, and $\beta$ is the installation angle of gauge cutter.
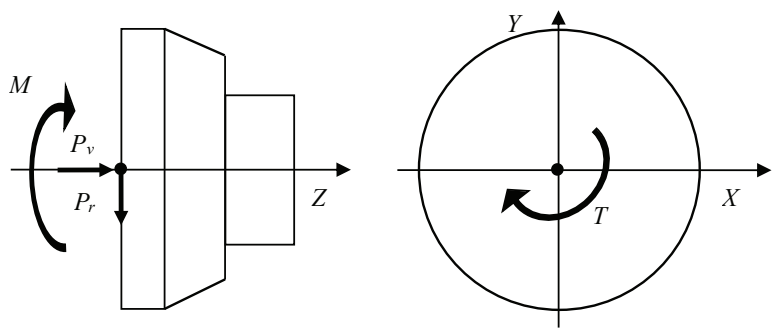

Figure 1. Cutterhead force. 

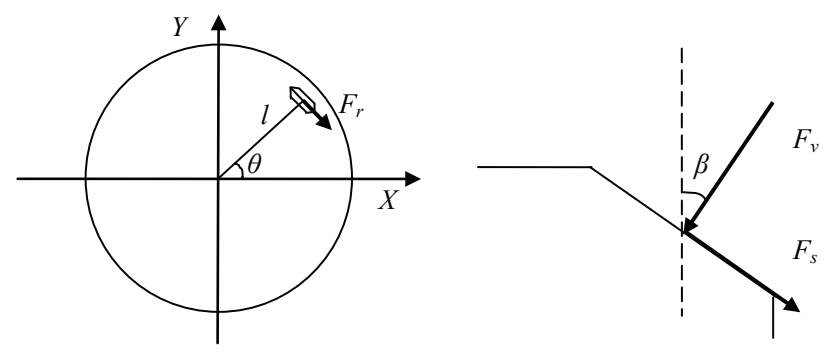

Figure 2. Cutter force and layout position.

\subsection{Cutter load model}

It is necessary to obtain the dynamic loads of each cutter, before solving the cutterhead loads. The cutter rock breaking force model developed at the Colorado School of Mines (CSM) was based on the experimental data, which was deduced by a regression analysis algorithm, and it had been verified in lots of projects with high precision (Rostami, 1997). However, in the CSM model, the cutter loads are static and calculated under the uniform geological condition. Actually, due to the rock inherent physical properties, the rock breaking forces are time-variant even in the uniform geologic section, which shows a certain degree of randomness. Concerning the randomness of cutter force, the test data indicated that it conformed to logarithmic normal distribution (Samuel and Seow, 1984; Zhang et al., 2003), as shown in Figure 3. Accordingly, in this study, it is assumed that the cutter force follows log-normal distribution, the mean value is calculated by CSM model, and the mean square deviation is obtained indirectly by counting the cutter force test data.

In the CSM model, the normal force $F_{v}$ and tangential force $F_{r}$ are expressed as follows:

$$
\begin{aligned}
& F_{v}=C \cdot T \cdot R \cdot \varphi \cdot\left(\frac{\sigma_{c}^{2} \sigma_{t} S}{\varphi \sqrt{R T}}\right)^{\frac{1}{3}} \cdot \cos \frac{\varphi}{2} \\
& F_{r}=C \cdot T \cdot R \cdot \varphi \cdot\left(\frac{\sigma_{c}^{2} \sigma_{t} S}{\varphi \sqrt{R T}}\right)^{\frac{1}{3}} \cdot \sin \frac{\varphi}{2}
\end{aligned}
$$

$$
\varphi=\arccos ((R-p) / R)
$$

where $\varphi$ is angle of the contact area, $\sigma_{c}$ is uniaxial compressive strength of rock, $\sigma_{t}$ brazilian indirect tensile strength of rock, $R$ is cutter radius, $S$ is cutter spacing, $p$ is cutter penetration, $T$ is cutter tip width, $C$ is constant equal 2.12 .

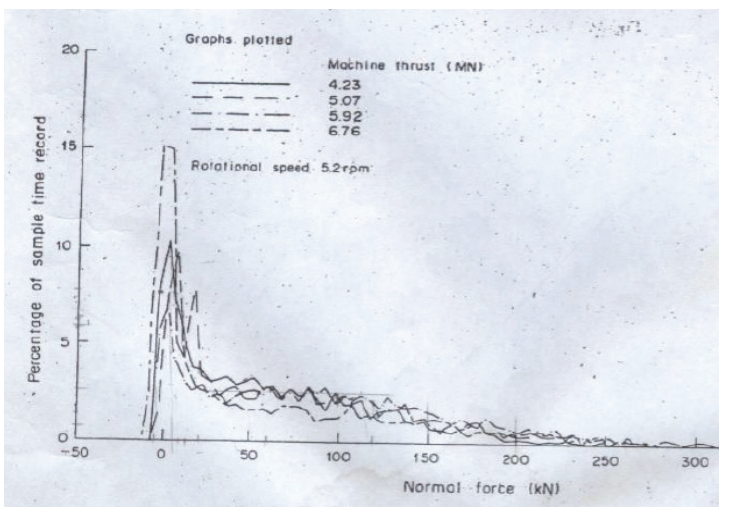

\subsection{Cutterhead excavation performance model}

After obtaining the cutters loads, the cutterhead loads can be combined according to the cutters location information. Then according to the specific energy definition, the time history of cutterhead specific energy can be obtained. The cutter side force direction is greatly related to the rock breaking way, so the randomness is obvious. Moreover, due to the cutter layout symmetry, the side forces can be approximately counteracted. Accordingly, the side forces have little influence on the cutterhead loads, which can be ignored. Besides, the cutterhead radial force is up and down balanced with small fluctuation when the cutterhead tunnels, which is considered as a constant load and can be equivalent to the cutterhead system gravity. Hence, the cutterhead torque, thrust and bending moment characteristics are mainly studied in this paper.

\subsubsection{Cutterhead torque}

Cutterhead torque $T$ is equal to the resultant torque of each tangential force around $Z$ axial, which can be expressed as:

$T=\sum_{i=1}^{n} F_{r i} l_{i}+\sum_{j=1}^{m} F_{r j} l_{j}+\sum_{k=1}^{q} F_{r k} l_{k}$

where $F_{r t}(t=i, j, k)$ is the tangential force of the $t$-th center cutter, normal cutter and gauge cutter, respectively, $n, m$ and $p$ are the number of the center cutter, normal cutter and gauge cutter, respectively, and $l_{t}(t=i, j, k)$ is the polar radius of the $t$-th center cutter, normal cutter and gauge cutter respectively.

\subsubsection{Cutterhead thrust}

Cutterhead thrust $P_{v}$ is equal to the resultant force in $Z$ direction of each cutter, with the following expression:

$P_{v}=\sum_{i=1}^{n} F_{v i}+\sum_{j=1}^{m} F_{v j}+\sum_{k=1}^{q} F_{v k} \cos \beta_{k}$

where $F_{v t}(t=i, j, k)$ is the normal force of the $t$-th center cutter, normal cutter and gauge cutter, respectively, and $\beta_{k}$ is the tilt angle of the $k$-th gauge cutter.

\subsubsection{Cutterhead bending moment}

Similarly, the cutterhead bending moment $M$ can be decomposed into two directions, which is equal to the vector sum of overturning moment $M_{x}$ and $M_{y}$, with the expressions showing in Eq. (6) Eq. (8).

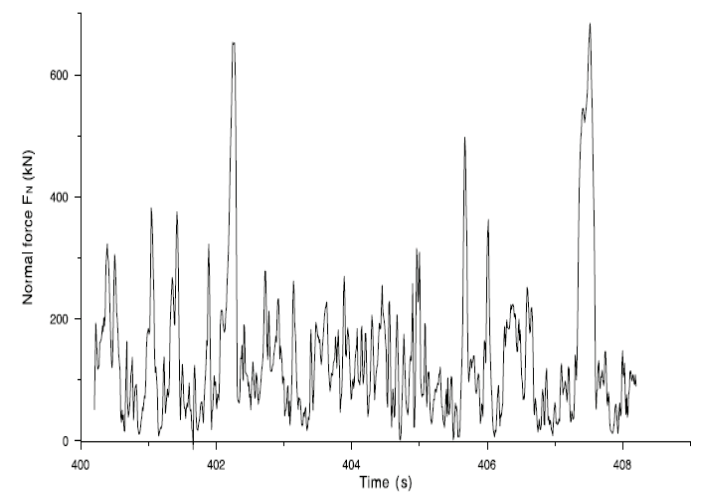

Figure 3. The measured forces of disc cutter rock crushing 


$$
\begin{aligned}
& M_{x}=\sum_{i=1}^{n} F_{v i} l_{i x}+\sum_{j=1}^{m} F_{v j} l_{j x}+\sum_{k=1}^{q} F_{v k} l_{k x} \cos \beta_{k} \\
& M_{y}=\sum_{i=1}^{n} F_{v i} l_{i y}+\sum_{j=1}^{m} F_{v j} l_{j y}+\sum_{k=1}^{q} F_{v k} l_{k y} \cos \beta_{k} \\
& M=\sqrt{M_{x}^{2}+M_{y}^{2}}
\end{aligned}
$$

where $l_{t x}(t=i, j, k)$ and $l_{t y}(t=i, j, k)$ are the distance to $X$ and $Y$ axis of the $t$-th cutter, respectively.

\subsubsection{Cutterhead specific energy}

The energy consumption of rock fragmentation per unit volume is defined as specific energy, which is an important basis for evaluating the cutter spacing. The cutterhead rock breaking energy is mainly produced by thrust and torque, so the specific energy $E_{s}$ can be expressed as:

$E_{s}=\frac{P_{v} p+2 \pi T}{\pi R_{d}^{2} p}$

where $R_{d}$ is the tunnel excavation radius.

\section{Project case}

The total length of the diversion tunnel in Liaoning Dahuofang water project is $85.31 \mathrm{~km}$, and the project is tunneled by $3 \mathrm{TBM}$ with $8.03 \mathrm{~m}$ excavation diameter. An American Robbins TBM is employed, with the whole machine showing in Figure 4, and the cutterhead system parameters are shown in Table 1. According to the statistics of geological exploration data, the typical soft rock and hard rock are mainly pelitic siltstone and granitic gneiss, and the rock mechanical property parameters are shown in Table 2.

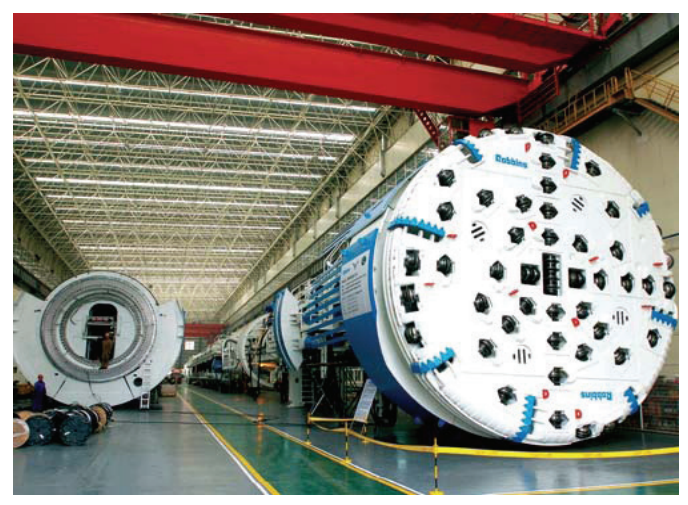

Figure 4. The physical model of TBM.
3.1. Spatial geological model in mixed-face rock ground condition

Based on the geological exploration report, a separation zone model for continuous tunneling is established, and the simulation length of two typical geology models is $100 \mathrm{~m}$. Using an interpolation algorithm in Matlab software, a three dimensional stratigraphic separation model is obtained, as shown in Figure 5, soft rock is above the separation zone, and hard rock is under it.

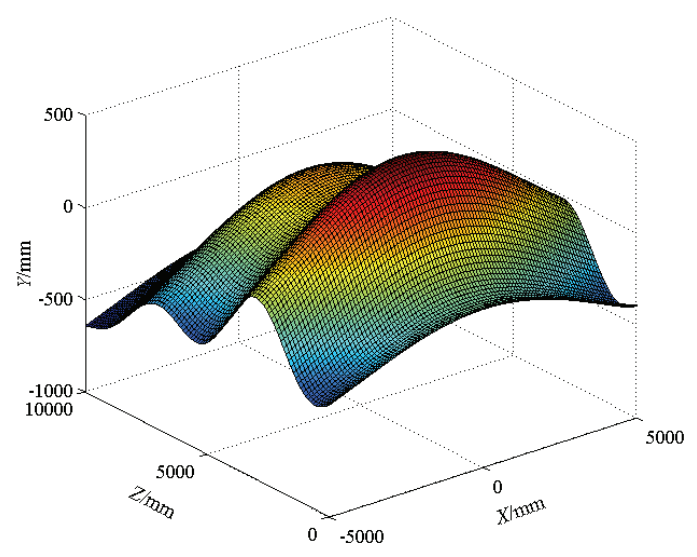

Figure 5. Geological model in typical engineering.

3.2. Numerical calculation and analysis of cutterhead loads in complex strata

The cutterhead loads numerical calculation is a process of continuously synthesizing the cutter forces and solving the cutterhead thrust, torque and bending moment, and the key step is to judge the surrounding rock property of each cutter at any time at the tunneling section in complex strata. The relative position of cutters and formation changed continually due to the cutterhead moving forward and rotating, which is the most influential factor of cutterhead loads fluctuation. Another important factor is the randomness of cutter rock breaking loads. In order to get the continuous cutterhead loads time-histories, the composite strata model and cutter position matrix are constructed, and then the numerical simulation analysis of the whole cutterhead excavation process is carried out based on the cutterhead tunneling parameters, cutter rock breaking load models and the field test data. The numerical solution process is shown in Figure 6.

\subsubsection{Cutter loads}

As mentioned above, based on the CSM model and cutter test loads data, the cutter loads are obtained under different conditions. With the conditions of $85 \mathrm{~mm}$ normal cutter spacing and rated penetration, the obtained loads of $30 \#$ cutter are presented in Figure 7.

Table 1 Parameters of cutterhead system.

\begin{tabular}{cccc}
\hline Cutterhead diameter $/ \mathrm{mm}$ & Rated speed $/ \mathrm{rpm}$ & Rated torque $/ \mathrm{kNm}$ & Rated thrust $/ \mathrm{kN}$ \\
\hline 8030 & 6 & 3490 & 13750 \\
\hline Driving power $/ \mathrm{kW}$ & Cutter number & Cutter diameter $/ \mathrm{mm}$ & Rated penetration $/(\mathrm{mm} / \mathrm{r})$ \\
\hline 3000 & 51 & 483 & 10 \\
\hline
\end{tabular}


Table 2 Mechanics parameters of typical rocks.

\begin{tabular}{ccccccc}
\hline \multirow{2}{*}{ Rock type } & $\begin{array}{c}\text { Density } /(\mathrm{g} / \\
\left.\mathrm{cm}^{3}\right)\end{array}$ & $\begin{array}{c}\text { Compression } \\
\text { strength/MPa }\end{array}$ & $\begin{array}{c}\text { Internal friction } \\
\text { angle } /\left(^{\circ}\right)\end{array}$ & $\begin{array}{c}\text { Cohesion / } \\
\mathrm{MPa}\end{array}$ & $\begin{array}{c}\text { Elastic modu- } \\
\text { lus } / \mathrm{GPa}\end{array}$ & $\begin{array}{c}\text { Poisson } \\
\text { ratio }\end{array}$ \\
\hline Pelitic siltstone & 2.61 & 42 & 33.8 & 1.2 & 9.6 & 0.30 \\
Granite gneiss & 2.75 & 93.6 & 33.4 & 0.9 & 18 & 0.19 \\
\hline
\end{tabular}

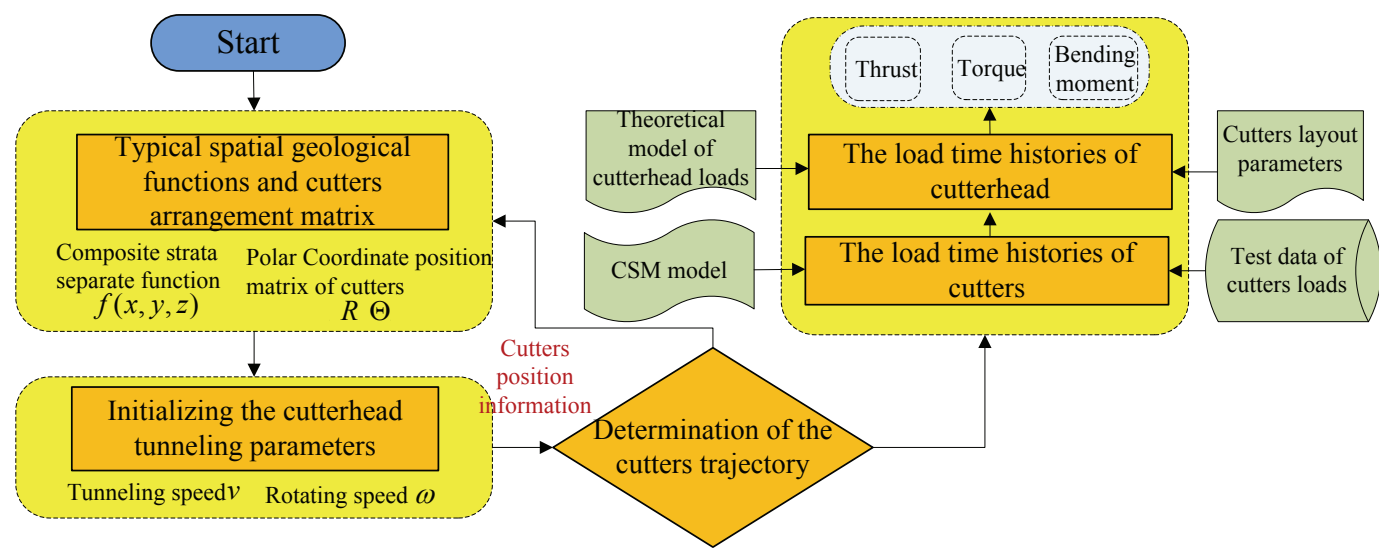

Figure 6. Numerical simulation process of cutterhead loads.

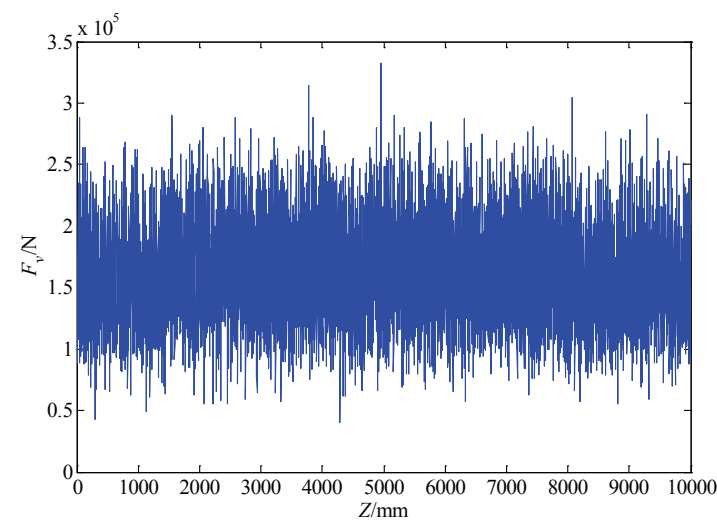

(a)

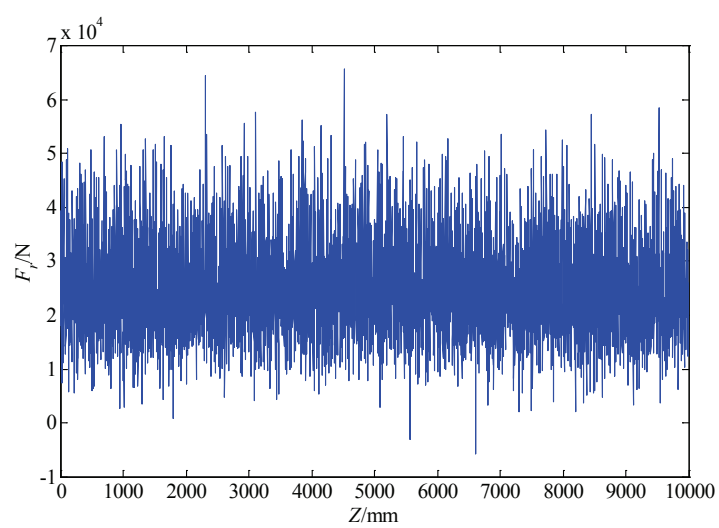

(b)

Figure 7. Loads of 30\# cutter (a) Normal force. (b) Tangential force.

\subsubsection{Torque characteristics}

According to engineering statistics, the TBM cutterhead normal cutter spacing is generally $40 \mathrm{~mm} \sim 120 \mathrm{~mm}$. Due to the installation position limit, the spacing less than $60 \mathrm{~mm}$ is seldom used. Accordingly, in this paper, the range of spacing value is limited to $75 \mathrm{~mm} \sim 115 \mathrm{~mm}$ when the influence of cutter spacing on the cutterhead tunneling performance is analyzed. Generally speaking, the value of cutter penetration depends on the rock properties at the cutterhead tunneling section. When the rock is hard, the penetration is taken as a smaller value appropriately and vice versa. So the range of penetration is defined as $2 \mathrm{~mm} \sim 10 \mathrm{~mm}$ in this study.

Based on the numerical simulation process of cutterhead loads in Figure 6, with the condition of penetration $p=10 \mathrm{~mm}$, the cutterhead torque along the tunneling direction under different normal cutter spacing values is obtained after substituting each parameter into Eq. (4), as shown in Figure 8(a). Similarly, the cutterhead torque under different penetration values is calculated with the condition of normal cutter spacing $S=85 \mathrm{~mm}$, as shown in Figure 8(b).

From the above results, when the cutter penetration $p=10 \mathrm{~mm}$ and the normal cutter spacing $S=85 \mathrm{~mm}$, the cutterhead torque fluctuates in the range of $2500 \sim 2900 \mathrm{kNm}$ approximately, which is basically consistent with the field cutterhead torque value in TBM tunneling state monitoring interface (as showed in Figure 9). It shows that the cutterhead loads calculation method and simulation process are reasonable and effective.

\subsubsection{Thrust characteristics}

Based on the numerical simulation process in Figure 6 and Eq. (5), the influence law of the normal cutter spacing and penetration on the cutterhead thrust can be also obtained, as shown in Figure 10. 


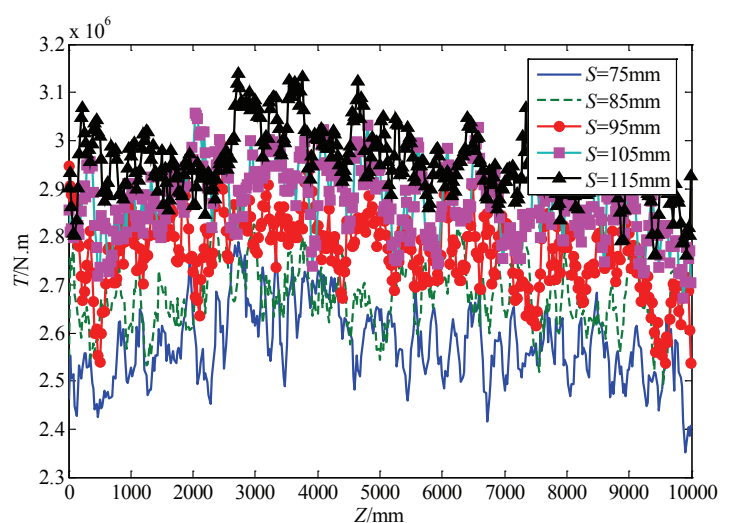

(a)

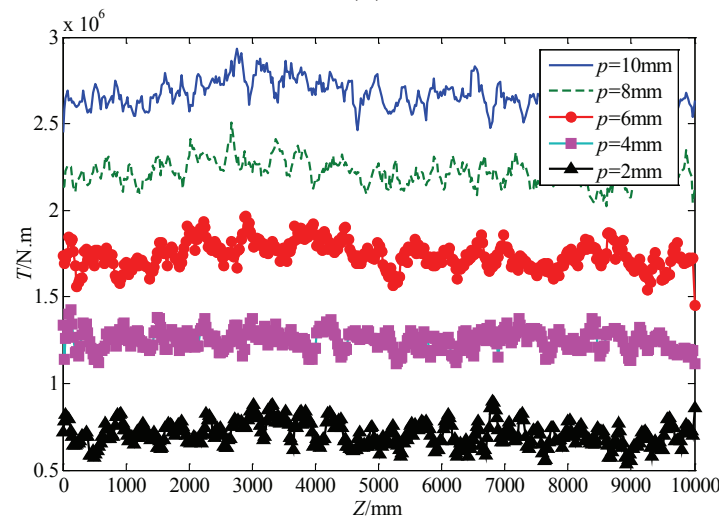

(b)

Figure 8. The influence of different parameters on cutterhead torque (a) Influence of cutter spacing ( $p=10 \mathrm{~mm})$. (b) Influence of penetration $(S=85 \mathrm{~mm})$.

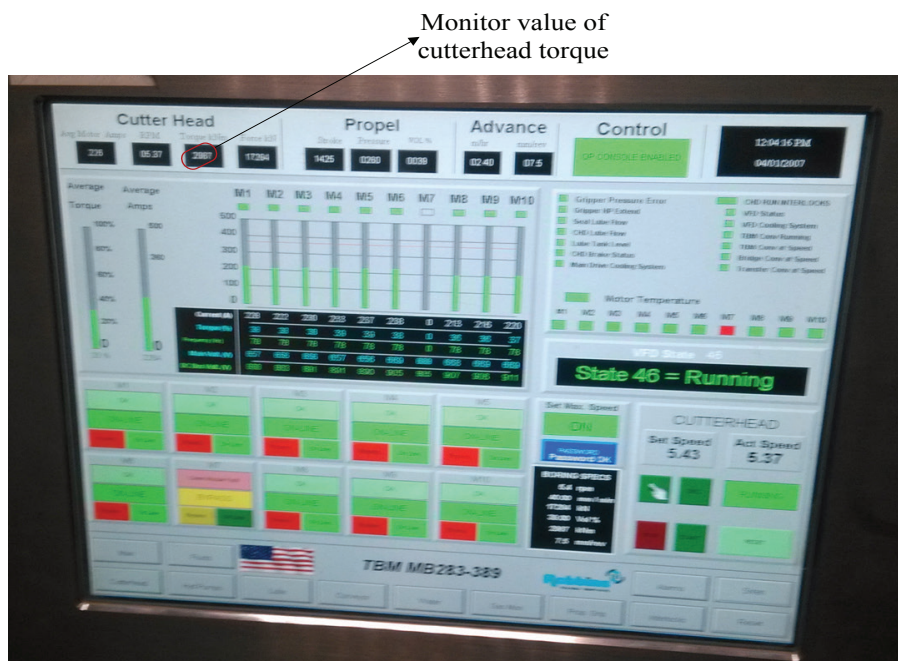

Figure 9. Tunneling state monitoring interface of field TBM.

\subsubsection{Bending moment characteristics}

In the same way, the influence law of the normal cutter spacing and penetration on the cutterhead bending moment are solved, as shown in Figure 11.

\subsection{Specific energy characteristics}

The obtained cutterhead torque and thrust, as well as the given parameters are substituted into Eq. (9), and the influence law of the normal cutter spacing and penetration on the cutterhead specific energy are analyzed, as the results shown in Figure 12.

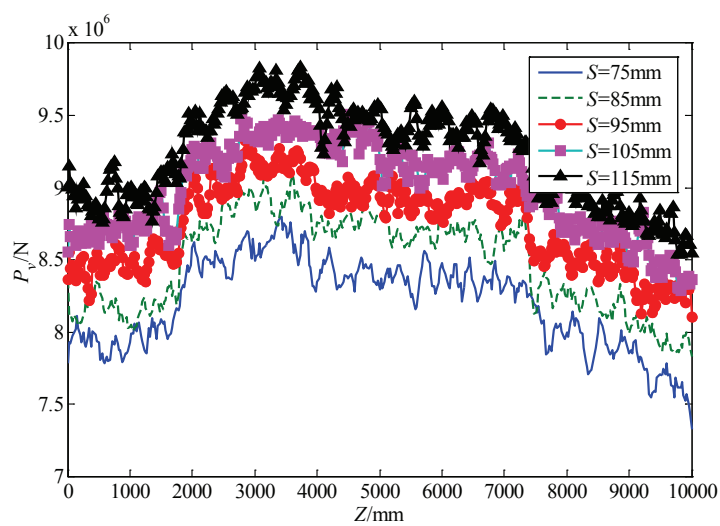

(a)

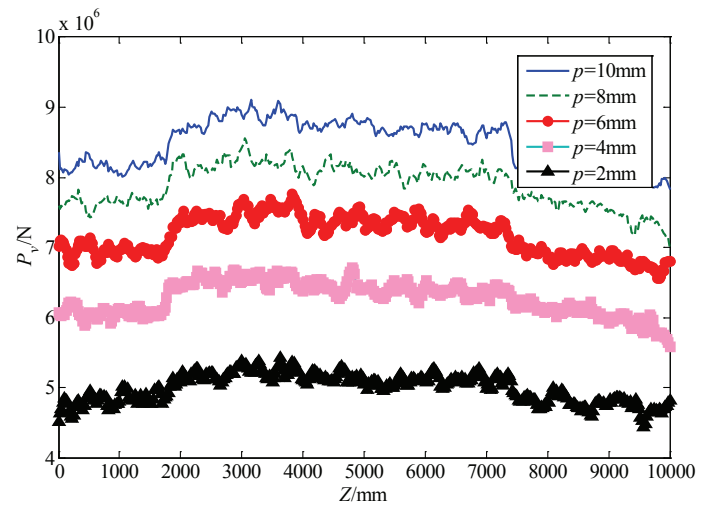

(b)

Figure 10. The influence of different parameters on cutterhead thrust (a) Influence of cutter spacing ( $p=10 \mathrm{~mm}$ ). (b) Influence of penetration $(S=85 \mathrm{~mm})$.

\subsection{Data statistics and analysis}

In order to further analyze the influence of the normal cutter spacing and penetration on the cutterhead performance, the mean value, standard deviation and coefficient of variation under different cutter spacing and penetration values are counted, with the statistical results showing in Table 3 and Table 4, respectively.

From the cutterhead tunneling performance influence rule and statistical results can be known:

(1) From Figure $8 \sim$ Figure 12 can be seen, the change regulation of the cutterhead tunneling performance under different normal cutter spacing and penetrations is basically identical, and the performance curves with each parameter show strong randomness.

(2) From the statistical data in Table 3 can be found, the cutterhead performance mean value increases with the normal cutter spacing. Under the working condition of penetration $p=10 \mathrm{~mm}$, the normal cutter spacing is increased from $75 \mathrm{~mm}$ to $115 \mathrm{~mm}$ (increased about 53\%), and the increase values of cutterhead torque and specific energy mean values are the maximum, which is about $15 \%$. Then the bending moment mean value increases about $14.7 \%$. Last, the thrust mean value increases about $12.6 \%$. 


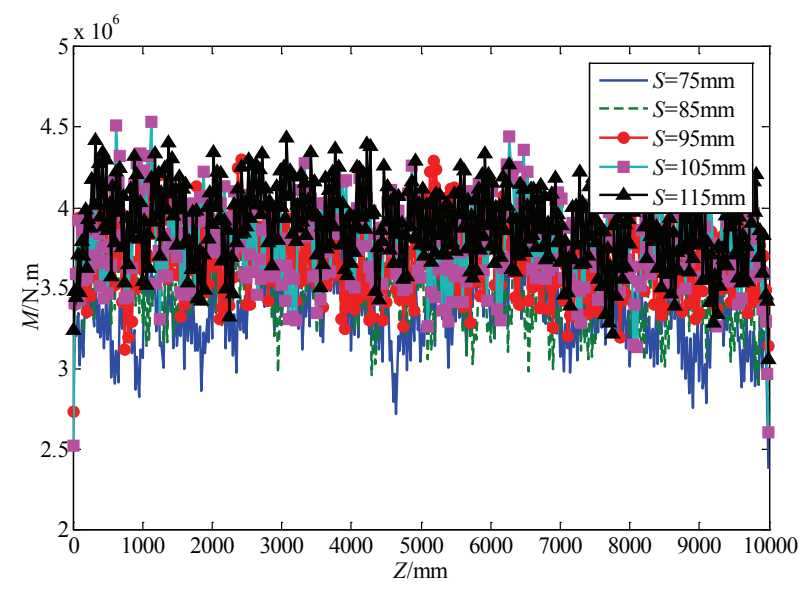

(a)

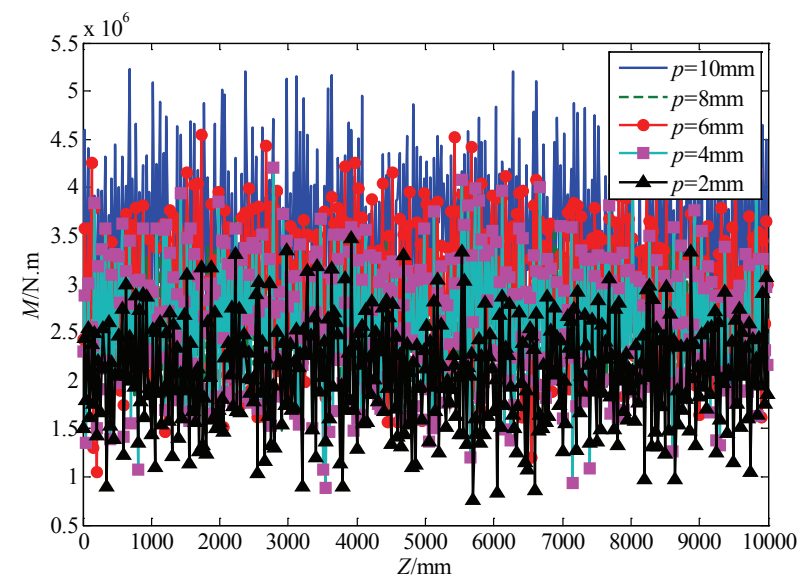

(b)

Figure 11. The influence of different parameters on cutterhead bending moment (a) Influence of cutter spacing $(p=10 \mathrm{~mm})$. (b) Influence of penetration $(S=85 \mathrm{~mm})$.

(3) From the statistical data in Table 4 can be known, the cutterhead torque, thrust and bending moment mean values are all increased with the penetration, yet the specific energy mean value is decreased with it. With the normal cutter spacing keeping constant in $85 \mathrm{~mm}$, when the penetration increases from $2 \mathrm{~mm}$ to $10 \mathrm{~mm}$, the increase value of torque mean value is the maximum, which increases about 3.8 times. And the mean values increment of thrust and bending moment are almost equal, which are about $69.7 \%$ and $68.1 \%$, respectively. In addition, the cutterhead specific energy mean value decreases by about $23.3 \%$.

(4) The change regulations of cutterhead tunneling performance standard deviations with normal cutter spacing and penetration can also be known from Table 3 and Table 4 . The cutterhead thrust and bending moment standard deviations show positive correlation with the two parameters, and the cutter spacing value increases by $53 \%$, thrust and bending moment standard deviations increase by about $4.2 \%$ and $9.4 \%$, respectively. Moreover, the penetration increases from $2 \mathrm{~mm}$ to $10 \mathrm{~mm}$, thrust and bending moment standard deviations increase by about $43 \%$ and $45.6 \%$, respectively. Besides, with the increase of normal cutter spacing, the cutterhead torque standard deviation shows a trend of first increase and then decrease. But with the increase of penetration, it presents an opposite tendency. With regard to

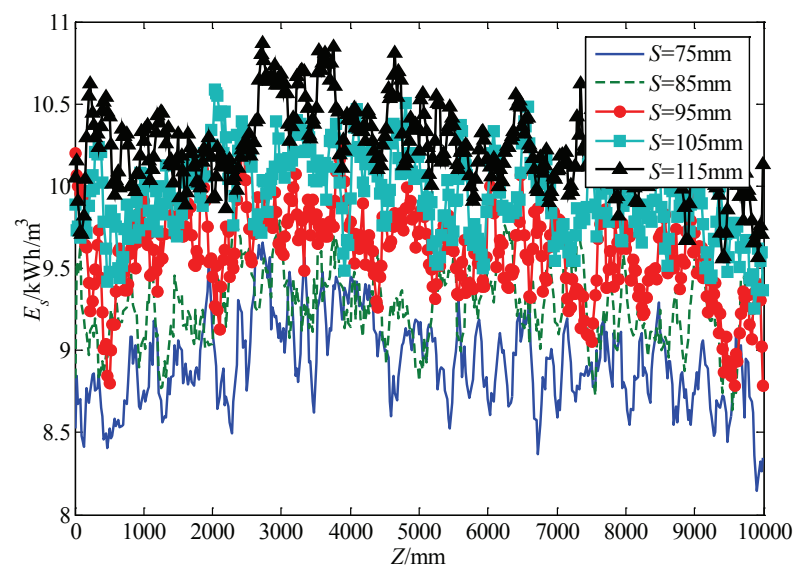

(a)

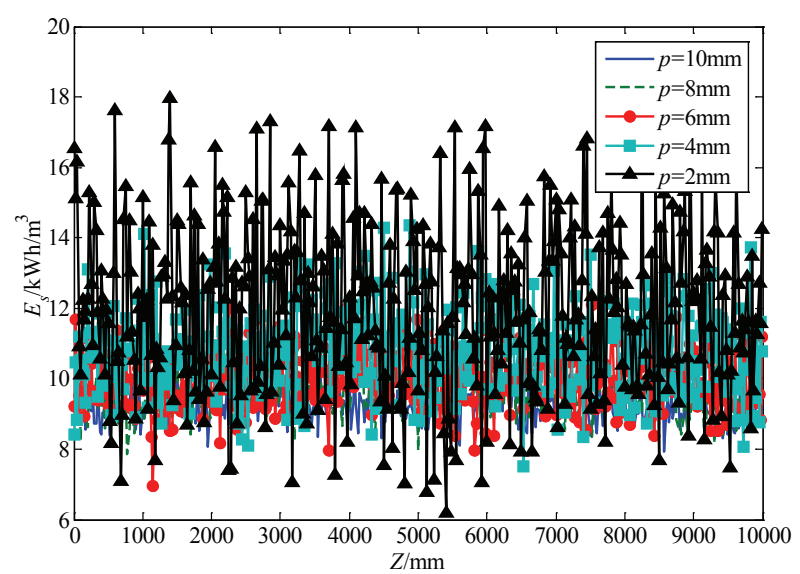

(b)

Figure 12. The influence of different parameters on cutterhead specific energy (a) Influence of cutter spacing ( $p=10 \mathrm{~mm}$ ). (b) Influence of penetration $(S=85 \mathrm{~mm})$.

the cutterhead specific energy standard deviation, it also shows a trend of first increase and then decrease with the increase of normal cutter spacing, and it shows an inverse correlation with penetration.

(5) Under the condition of penetration $p=10 \mathrm{~mm}$, the cutterhead bending moment coefficient of variation magnitude are greater than other indexes, which is more than $20 \%$, and the values of other indexes are about $5 \%$. It indicates that the unit average dispersion degree of bending moment is the maximum. In addition, with the increase of normal cutter spacing, almost all the indexes coefficient of variation decreases in different degrees except the bending moment. When the normal cutter spacing is equal to $95 \mathrm{~mm}$, the bending moment coefficient of variation is the minimum. From the point view of reducing the average vibration intensity of cutterhead bending moment, it demonstrates that the optimal value of normal cutter spacing is $95 \mathrm{~mm}$ under this condition.

(6) When the normal cutter spacing is equal to $85 \mathrm{~mm}$, with the increase of penetration, the cutterhead thrust and bending moment coefficient of variations are basically remain unchanged, which indicates that the penetration has little effect on the average dispersion degree of the two indexes. However, the penetration has a great impact on the cutterhead torque and 
specific energy coefficient of variations. The penetration is increased from $2 \mathrm{~mm}$ to $10 \mathrm{~mm}$, the two coefficient of variations all decrease by about $73 \%$. It shows that proper increase of penetration is beneficial to reduce the average vibration intensity of cutterhead torque and specific energy.

\section{Conclusions}

A spatial three-dimensional separation zone model for cutterhead tunneling under the typical geology is established, based on the geological exploration data of TBM tunneling sections. Then a prediction method of TBM cutterhead dynamic tunneling performance under the typical geological conditions is proposed, which comprehensively considers the tunneling parameters, cutter layout information and the tunneling section rock dynamic changes, on the basis of the multi-cutters CSM model and field test statistic data. Last, taking an actual TBM cutterhead system as an example, the proposed prediction method is used to program a numerical simulation process for cutterhead dynamic loads, and the dynamic cutters loads, cutterhead tunneling loads and specific energy are obtained. Besides, the influences of the normal cutter spacing and penetration on the cutterhead performance are analyzed, and a series of qualitative and quantitative conclusions are obtained. The main conclusions can be drawn as follows:

(1) The change laws of cutterhead tunneling performance curves with different parameters are basically identical.

(2) The cutterhead loads have a positive correlation with the normal cutter spacing and penetration, and the specific energy is positively related to the normal cutter spacing but negatively related to penetration.

(3) Under the working condition of penetration $p=10 \mathrm{~mm}$, the cutterhead bending moment coefficient of variation magnitude exceeds $20 \%$, and the optimal value of the normal cutter spacing is $95 \mathrm{~mm}$ at this situation.

(4) When the normal cutter spacing is equal to $85 \mathrm{~mm}$, the penetration has a greater influence on the torque and specific energy coefficient of variations, which indicates that proper increase of penetration is beneficial to reduce the average vibration intensity of the two indexes. The proposed prediction method of TBM cutterhead dynamic tunneling performance and the engineering practice numerical analysis results can provide reference for TBM cutterhead layout and tunneling parameters matching.

Acknowledgements This work is financially supported by the National Natural Science Foundation of China (51775113), the Natural Science Foundation of Fujian Province, China (2017J01675), and Scientific Research Foundation of Fujian University of Technology (GY-Z160048).

Conflict of interest The authors declare that they have no conflict of interest.

\section{References}

[1] Huo J. Z., Wu H. Y., Sun W., Zhang Z.G., Wang L. P., Dong J.H., 2017. Electromechanical coupling dynamics of TBM main drive system. Nonlinear Dynamics, 90, 2687-2710.

[2] Chai B. M., Bai Y. L., Liu J. Q., Li L. L., 2017. Research on multiple damage of remanufacturing TBM cutterhead. Journal of Hebei University of Engineering (Natural Science Edition), 34, 109-112.

[3] Samuel A.E., Seow L.P., 1984. Disc force measurements on a full-face tunnelling machine. International Journal of Rock Mechanics \& Mining Sciences \& Geomechanics Abstracts, 21,83-96.

[4] Rostami J., 1997. Development of a force estimation model for rock fragmentation with disc cutters through theoretical modeling and physical measurement of crushed zone pressure. Colorado: Colorado School of Mines. Department of Mining Engineering.

[5] Zhang Z.X., Kou S.Q., Lindqvist P.A., 2003. In-situ measurements of cutter forces on boring machine at Äspö hard rock laboratory part II. characteristics of cutter forces and examination of cracks generated. Rock Mechanics \& Rock Engineering, 36, 63-83.

[6] Gertsch R., Gertsch L., Rostami J., 2007. Disc cutting tests in Colorado Red Granite: Implications for TBM performance prediction. International Journal of Rock Mechanics \& Mining Sciences, 44, 238-246.

[7] Entacher M., Winter G., Galler R.,2013. Cutter force measurement on tunnel boring machines-Implementation at Koralm tunnel. Tunnelling \& Underground Space Technology Incorporating Trenchless Technology Research, 38, 487-496.

[8] Jeong H. Y., Cho J. W., Jeon S., Rostami J., 2015. Performance assessment of hard rock TBM and rock boreability using punch penetration test. Rock Mechanics \& Rock Engineering, 49, 1-16.

[9] Yang H., Wang H., Zhou X., 2016. Analysis on the rock-cutter interaction mechanism during the TBM tunneling process. Rock Mechanics \& Rock Engineering, 49,1073-1090.

[10]Xiao N., Zhou X. P., Cheng H., Zhai S.F., 2015. Mechanism of rock fragmentation by TBM cutters using 3D FEM-SPH coupling method. Journal of China Coal Society, 40, 12631269.

[11]Liu J. Q., Liu M. M., Guo W., 2015. Research on the simulation of cutting rock rotary by hard rock tunnel boring machine disc cutters. Journal of Mechanical Engineering, 51,199-205.

[12] Geng Q., Wei Z., Ren J.,2017. New rock material definition strategy for FEM simulation of the rock cutting process by TBM disc cutters. Tunnelling \& Underground Space Technology, 65,179-186.

[13]Xia Y. M., Guo B., Cong G. Q., Zhang X. H., Zeng G. Y.,2017. Numerical simulation of rock fragmentation induced by a single TBM disc cutter close to a side free surface. International Journal of Rock Mechanics \& Mining Sciences, 91, 40-48.

[14]Jiang M., Liao Y., Wang H.,2017. Distinct element method analysis of jointed rock fragmentation induced by TBM cutting. European Journal of Environmental \& Civil Engineering, 7,1-20.

[15]Xia Y. M., Tian Y. C., Tan Q., Hou Y. M.,2016. Side force formation mechanism and change law of TBM center cutter. Journal of Central South University, 23,1115-1122.

[16]Geng Q., Wei Z., Meng H., 2016. An experimental research on the rock cutting process of the gage cutters for 
rock tunnel boring machine (TBM). Tunnelling and Underground Space Technology, 52,182-191.

[17]Zhu X. H.,2014. Research on distribution characteristic of excavation load on TBM cutterhead. Changsha: Central South University.

[18]Liu J., Ren J., Wei G.,2015. Thrust and torque characteristics based on a new cutter-head load model. Chinese Journal of Mechanical Engineering, 28, 801-809.

[19]Liu J. Q., Bin H. C., Guo W.,2019. Study on load characteristics of TBM cutterhead under mixed-face rock ground condition. Journal of Harbin Engineering University, doi:10.11990/jheu.201609049.

[20]Huang T., Wang X. L., Liu H. T., Yang Y. H., 2016. Force analysis of an open TBM gripping-thrusting-regripping mechanism. Mechanism \& Machine Theory, 98,101-113.

[21]Han M.D., Cai Z. X., Qu C. Y., Jin L. S.,2017. Dynamic numerical simulation of cutterhead loads in TBM tunneling. Tunnelling \& Underground Space Technology, 70, 286298.

[22] Rostami J.,2008. Hard rock TBM cutterhead modeling for design and performance prediction. Geomechanics \& Tunnelling, 1,18-28.

[23] Geng Q., Wei Z. Y., Meng H., Francisco J. M., 2016. Mechanical performance of TBM cutterhead in mixed rock ground conditions. Tunnelling \& Underground Space Technology Incorporating Trenchless Technology Research, 57,76-84.

[24]Geng Q., Wei Z. Y., Meng H., Francisco J. M., Amund
B.,2016.Free-face-assisted rock breaking method based on the multi-stage tunnel boring machine (TBM) cutterhead. Rock Mechanics \& Rock Engineering, 49,4459-4472.

[25]Huo J. Z., Wu H. Y., Yang J., Sun W., Li G. Q., Sun X. L.,2015. Multi-directional coupling dynamic characteristics analysis of TBM cutterhead system based on tunnelling field test. Journal of Mechanical Science and Technology, 29,3043-3058.

[26]Huo J. Z., Hou N., Sun W., Wang L.P., Dong J.H., 2016. Analyses of dynamic characteristics and structure optimization of tunnel boring machine cutter system with multijoint surface. Nonlinear Dynamics, 1,1-18.

[27]Avunduk E., Copur H.,2018. Empirical modeling for predicting excavation performance of EPB TBM based on soil properties. Tunnelling \& Underground Space Technology, 71,340-353.

[28]Wang L.H., Kang Y.L., Cai Z.X., Zhao Y., Zhao H.F., Su P.C.,2012. The energy method to predict disc cutter wear extent for hard rock TBMs. Tunnelling \& Underground Space Technology Incorporating Trenchless Technology Research, 28,183-191.

[29]Mirahmadi M., Tabaei M., Dehkordi M. S.,2017. Estimation of the specific energy of TBM using the strain energy of rock mass, case study: Amir-Kabir water transferring tunnel of Iran. Geotechnical and Geological Engineering, 35,1991-2002. 